\title{
Survival of low birthweight neonates in Uganda: analysis of progress between 1995 and 2011
}

Malachi Ochieng Arunda* ${ }^{*}$, Anette Agardh and Benedict Oppong Asamoah

\begin{abstract}
Background: Although low birthweight (LBW) babies represent only $15.5 \%$ of global births, it is the leading underlying cause of deaths among newborns in countries where neonatal mortality rates are high. In Uganda, like many other sub-Saharan African countries, the progress of reducing neonatal mortality has been slow and the contribution of low birthweight to neonatal deaths over time is unclear. The aim of this study is to investigate the association between low birthweight and neonatal mortality and to determine the trends of neonatal deaths attributable to low birthweight in Uganda between 1995 and 2011.
\end{abstract}

Methods: Cross-sectional survey datasets from Uganda Demographic and Health Surveys between 1995 and 2011 were analyzed using binary logistic regression with 95\% confidence interval (Cl) and Kaplan-Meier survival analysis to examine associations and trends of neonatal mortalities with respect to LBW. A total of 5973 singleton last-born live births with measured birthweights were included in the study.

Results: The odds of mortality among low birthweight neonates relative to normal birthweight babies were; in 1995, 6.2 (95\% Cl 2.3 -17.0), in 2000-2001, 5.3 (95\% Cl 1.7 -16.1), in 2006, 4.3 (95\% Cl 1.3 - 14.2) and in 2011, 3.8 ( $95 \% \mathrm{Cl} 1.3$ - 11.2). The proportion of neonatal deaths attributable to LBW in the entire population declined by more than half, from 33.6\% in 1995 to $15.3 \%$ in 2011. Neonatal mortality among LBW newborns also declined from $83.8 \%$ to $73.7 \%$ during the same period.

Conclusion: Low birthweight contributes to a substantial proportion of neonatal deaths in Uganda. Although significant progress has been made to reduce newborn deaths, about three-quarters of all LBW neonates died in the neonatal period by 2011. This implies that the health system has been inadequate in its efforts to save LBW babies. A holistic strategy of community level interventions such as improved nutrition for pregnant mothers, prevention of teenage pregnancies, use of mosquito nets during pregnancy, antenatal care for all, adequate skilled care during birth to prevent birth asphyxia among LBW babies, and enhanced quality of postnatal care among others could effectively reduce the mortality numbers.

Keywords: Low birthweight, Attributable neonatal mortality, Logistic regression, Kaplan-Meier survival analysis, Cross-sectional

\footnotetext{
* Correspondence: arundamalachi@gmail.com

Social Medicine and Global Health, Department of Clinical Sciences, Lund

University, Jan Waldenströms gata 35, 20502 Malmö, Sweden
}

(c) The Author(s). 2018 Open Access This article is distributed under the terms of the Creative Commons Attribution 4.0 International License (http://creativecommons.org/licenses/by/4.0/), which permits unrestricted use, distribution, and reproduction in any medium, provided you give appropriate credit to the original author(s) and the source, provide a link to the Creative Commons license, and indicate if changes were made. The Creative Commons Public Domain Dedication waiver (http://creativecommons.org/publicdomain/zero/1.0/) applies to the data made available in this article, unless otherwise stated. 


\section{Background}

About 20 million low birthweight (LBW) babies are born every year, representing $15.5 \%$ of all births globally [1]. Over 95\% of all LBW cases occur in low-income countries [1]. Of recent, Lawn et al. and the World Health Organization (WHO) estimated that LBW contributes to $60-80 \%$ of all neonatal deaths (death within 28 days after birth) worldwide [2, 3]. However, wider disparities in estimates exist between countries. India, a low-to-middle income country, contributes about $40 \%$ of global burden of LBW babies [4], and in 2013, 48\% of all neonatal deaths in India were attributed to LBW and preterm birth [5]. In comparison to Sweden, a high-income country where neonatal mortality is very low (1.5 per 1000 live births in 2014) [6], LBW babies constituted only $3.2 \%$ of national live birth in 2014, and barely $4.3 \%$ of all neonatal deaths in 2014 were LBW cases [6]. WHO defines LBW as birthweight of less than $2500 \mathrm{~g}$ [1]. LBW is mainly a result of preterm births and restricted fetal growth (resulting in small for gestational age (SGA) babies) or both [1]. The main risk factors leading to LBW include young mothers/short stature of the mother [7], multiple births [8], poor nutrition before conception and during pregnancy (poverty) [9], smoking [10], maternal HIV positivity, and malaria during pregnancy $[11,12]$.

In sub-Saharan Africa (SSA), the general rate of decline in neonatal mortality (NM) has been slow compared to infant or under-five mortality [13] and more than half of all births do not take place in health facilities [14]. An individual participant level meta-analysis study in four district projects within East Africa (EA) in 2012 estimated that $52 \%$ of all neonatal deaths in Kenya, Uganda, and Tanzania were attributable to preterm birth or small for gestational age, of which $99 \%$ were LBW babies [15]. Several neonatal and infant mortality studies in SSA fall short of determining the contribution of LBW to neonatal deaths. Whereas LBW is the underlying cause of majority of neonatal deaths, most studies have focused on other leading direct causes of neonatal deaths such as birth asphyxia, infections, and preterm birth [16-18]. Another 5-year health facility-based study in Ghana estimated that LBW was a sole contributor of $50 \%$ of neonatal deaths in the facility between 2008 and 2012 [19]. While LBW can be a result of preterm birth, it is also a notable fetal risk factor for birth asphyxia and infections such as sepsis $[17,18]$.

In Uganda, like in many SSA settings, apart from health system limitations such as inadequate resources, paucity of data in hospital registries makes it difficult to determine the prevalence of LBW and associated mortality trends [20, 21]. The 2008 situation analysis report indicated that neonatal deaths were not registered in Uganda; no countrywide perinatal audit exists [20]. The
2006 retrospective demographic survey in Uganda estimated that $60 \%$ of newborn deaths occurred at home [22]. The Uganda roadmap for reducing neonatal mortality 2007-2015 fell short of incorporating LBW among the causes of neonatal deaths [21], possibly due to challenges in determining LBW-attributable deaths. No studies that determined the national trends of LBW-attributable neonatal mortality in Uganda were identified by our literature search, despite being a key indicator of population and reproductive health in a country [2]. However, in order for Uganda to achieve the global Sustainable Development Goal (SDG) target 3.2 that aims to drastically reduce neonatal mortality by 2030 [23], the contribution of LBW towards neonatal mortality can no longer remain unclear. Although LBW is estimated to contribute about $80 \%$ of neonatal deaths in SSA [3], efforts to reduce neonatal mortality from the inception of the Millennium Development Goals (MDGs) in 1990 to its end in 2015 in Uganda have never been evaluated in terms of reduction of LBW-attributable deaths. Further, there are no national representative studies that have examined the contribution of LBW toward the overall neonatal mortality in Uganda. This present study thus aims to determine both the association between LBW and neonatal mortality in Uganda and to estimate the national trends of LBW-attributable neonatal mortality between 1995 and 2011. This period covered the entire MDG period except for the last 4 years to 2015 .

\section{Methods}

\section{Study setting and maternal health situation}

With an annual population growth rate of about 3.2 and an overall fertility rate of 5.6, Uganda's population rose from about 17 million in the 1990 s to about 34 million in 2011 [24]. The sex ratio is $1: 1$ and the adolescence fertility rate was about 131 per 1000 births in 2010 [25]. Over $77 \%$ of the population live in rural areas. The national poverty levels notably reduced from $38.8 \%$ in 2002-2003 to about 20\% in 2012-2013 [26]. However, poverty levels differ significantly by region and sub-regions. For instance, while incidence of poverty in the northern region in 2013 was $44 \%$, it was only $5.1 \%$ in the central region [26]. In March 2001, Uganda abolished user fees in first level government health facilities and this included maternal health services [27]. The proportion of four or more antenatal care visits was still less than $50 \%$ by 2011 [28]. Incrementally, by 2011 about $57 \%$ of total births took place in health facilities and the proportion of births that received post-natal care increased from less than $10 \%$ in 1995 to $26 \%$ in 2006 and to $32 \%$ in 2011 [28, 29].

\section{Study design and data source}

We obtained secondary data from repeated cross-sectional surveys by the Demographic and Health Survey (DHS) 
program. The datasets are independent and nationally representative. We used four datasets from the Uganda DHS birth recodes for the years 1995, 2000-2001, 2006, and 2011. A total of 5973 singleton last-born live births with birthweight measures were included in the study. This consisted of 1160 children in 1995 representing 25\% of all the last-born live births in the data sample for that year and 1100 children for the year 2000-2001 representing 30\% of all the last-born live births in the sample for that year. Similarly, 1514 (35\%) children were included for the year 2006 and 2199 (50\%) for the year 2011. We targeted and utilized the birth recode information for the last-born live births born within the 5-year period prior to each of the surveys. The Demographic and Health Survey (DHS) program employs standardized questionnaires and protocols that ensure that the participants remain anonymous [30,31]. The DHS data collection procedure involves stratified two-stage cluster sampling and collection of data countrywide using updated lists of enumeration areas for each of the surveys to avoid overlap and improve national representativeness of the data [32]. Further information on data sampling and collection criteria are detailed in the DHS field manuals and methodology toolkits [30-32].

\section{Variables}

\section{Outcome variable}

Neonatal mortality This referred to death of newborn within 28 days after birth. It was dichotomized into yes (died) or no (alive).

\section{Predictor variable}

Low birthweight The variable low birthweight (LBW) was the predictor variable. Birthweight records were obtained from the child's health card or from the mother's verbal report of measured weight at birth. Birthweight was dichotomized into LBW (<2500 g) or normal birthweight $(\mathrm{NBW}) \geq 2500 \mathrm{~g}$. Macrosomia (>4000 g) [33] was eliminated in the univariate and logistic regression analyses involving birthweights. The higher neonatal mortality risks of macrosomia relative to NBW [34] would reduce the accuracy of our findings if they are included among NBW numbers. At the hospital, newborns are weighed and their birthweights recorded on the child's health card and is communicated. In contrast, for births outside the health facility such as home births, birthweight is likely to be estimated by observing the birth size of body parts, the accuracy of which is questionable. To improve the accuracy of reported birthweight, whether recall or from the health card, only hospital births were included in the study for the years 2000-2001, 2006, and 2011. For the 1995 dataset, however, we also included the very few home birth cases in our sample in order to improve the statistical power of our analyses. Records of the size of the babies registered as small or average among others were excluded from the study to minimize errors of misclassification due to the unreliable subjective nature of the categorization criteria [35]. From the study's selected samples, $72 \%$ of the 1160 selected sample in 1995 had birthweight from mothers' recall and the rest were from health cards. Similarly, in $2000,79 \%$ of the 1100 selected sample were from recall. In 2006, $73.5 \%$ of the total 1514 were recall birthweights and in 2011, 67\% of the total 2199 were recall birthweights.

Preterm birth, LBW and birth asphyxia are highly correlated and it is difficult to determine their independent contributions towards neonatal deaths. These three, together with infections, contribute to $80 \%$ of neonatal mortality as the highest cause of neonatal mortality, with LBW being the underlying factor [36].

\section{Maternal and socio-demographic variables}

In this study, independent variables that are known to be direct and indirect risk factors for neonatal mortality and LBW such as 'young' maternal age (7) and poor nutrition (resulting from poverty and low or no education (9) were investigated. Wealth status was determined as a composite cumulative living standard measured in terms of household asset inventory. These were investigated in the univariate analysis to determine their distribution and possible associations with birthweight and neonatal survival categories. Smoking was not examined due to lack of data. Figure 1 below shows a conceptual visualization of LBW as an overriding cause of the majority of neonatal deaths.

Below (Table 1) is a summary of outcome and predictor variables and the covariates that influence the occurrence of low birthweight and the survival of neonates.

\section{Data analysis}

We used analytical software IBM SPSS version 24 and MS excel for analyses. Pearson's chi square test of independence and association was used to examine the distribution of variables according to birthweight and neonatal mortality for each survey. Survival plots of the birthweight categories were generated using Kaplan-Meier's estimator. Binomial logistic regression analysis was used to determine the odds ratios for the association between LBW and neonatal mortality after adjusting for socio-demographic and maternal factors, cesarean births and check-ups for pregnancy complications. The analysis was conducted at $5 \%$ significant level. In order to improve the validity of the results, the national representativeness of the data and to adjust for non-response, the complexity of DHS sampling design was taken into account, and data sampling weights were applied to datasets for the years 


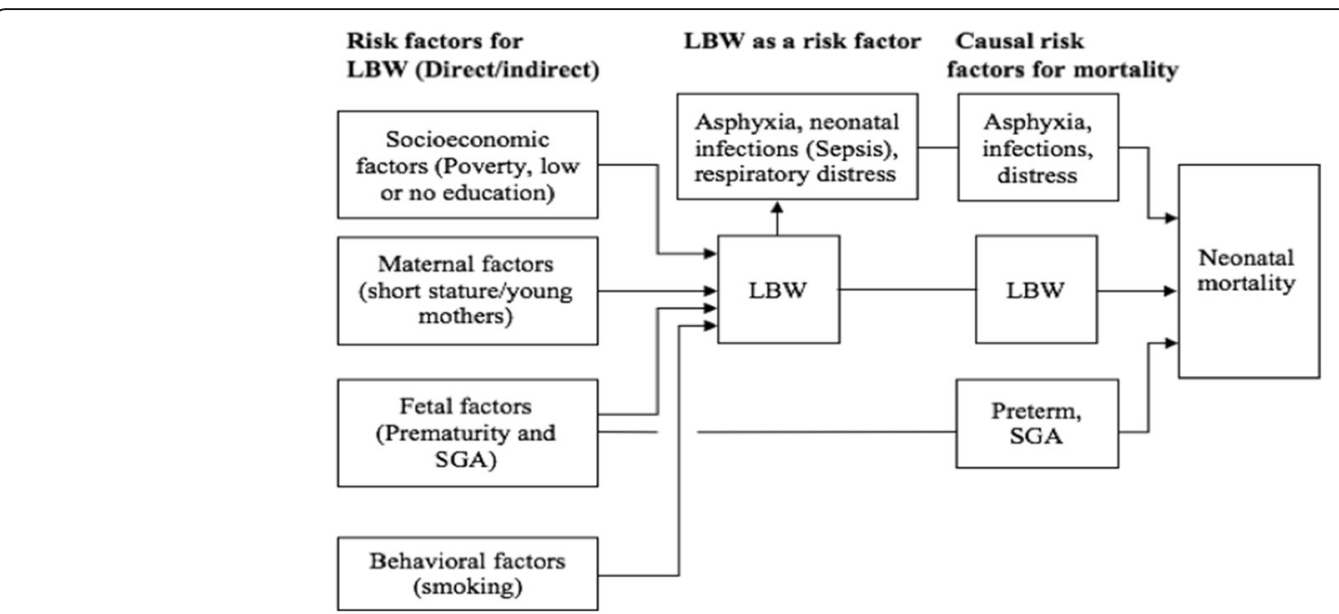

Fig. 1 Conceptual visualization of potential risk factors leading to LBW and neonatal mortality. LBW - Low birthweight, SGA - Small for gestation age

Table 1 Summary of variables

\begin{tabular}{|c|c|c|}
\hline Variables & Categories & Descriptions \\
\hline \multicolumn{3}{|l|}{ Outcome variable } \\
\hline \multirow[t]{2}{*}{ Neonatal mortality } & Yes (Dead) & Died within age $\leq 1$ month \\
\hline & No (Alive) & Alive at age $\geq 1$ month \\
\hline \multicolumn{3}{|l|}{ Predictor variable } \\
\hline \multirow[t]{2}{*}{ Low birthweight } & Yes & $<2500 \mathrm{~g}$ \\
\hline & No & $\geq 2500 \mathrm{~g} \leq 4000 \mathrm{~g}$ \\
\hline \multicolumn{3}{|l|}{ Maternal and socio-economic variables } \\
\hline \multirow[t]{3}{*}{ Maternal age } & $<20$ years & \\
\hline & 20-34 years & \\
\hline & $35-49$ years & \\
\hline \multirow[t]{2}{*}{ Wealth status } & Poor & \\
\hline & Middle/rich & \\
\hline \multirow[t]{3}{*}{ Maternal education } & No education & No formal education \\
\hline & Primary & $<9$ years of education \\
\hline & Secondary/higher & $\geq 9$ years of education \\
\hline \multirow[t]{3}{*}{ Parity } & Primiparous & First ever birth \\
\hline & Para 2-3 & 2-3 children \\
\hline & Para 4+ & 4 or more children \\
\hline \multirow[t]{2}{*}{ Marital status } & Single & $\begin{array}{l}\text { Never married, widowed, separated/divorce } \\
\text { at delivery time, not living with the spouse }\end{array}$ \\
\hline & Married & Married or cohabiting \\
\hline \multirow[t]{2}{*}{ Place of residence } & Rural & \\
\hline & Urban & \\
\hline \multirow[t]{2}{*}{ Cesarean birth } & No & \\
\hline & Yes & \\
\hline \multirow[t]{2}{*}{ Check-up for pregnancy complications } & No & \\
\hline & Yes & \\
\hline
\end{tabular}


2000-2001, 2006, and 2011. However, the 1995 dataset was not subjected to weighting due to the need to maintain the statistical power of the data for that year, the implication of which is a very minimal difference. A total of 5973 last-born live births with birthweights were included in the analyses.

\section{Estimation of LBW-attributable mortality risk fraction among LBW neonates and in the population}

The LBW-attributable neonatal mortality risk fraction (AF) and population-attributable mortality risk fraction (PAF) were computed as proportion of prevalent deaths that could be avoided if LBW was prevented or the death of LBW babies was eliminated. These were calculated manually using eqs. (1) and (2) below.

$$
\mathrm{AF}=\left(\frac{O R-1}{O R}\right) * 100
$$

The population attributable mortality risk fraction PAF, expressed as a percentage (\%) was computed using the eq. (2).

$$
\mathrm{PAF}=\mathrm{P}_{\mathrm{e}}{ }^{*} \mathrm{AF}=\mathrm{P}_{\mathrm{e}} *\left(\frac{O R-1}{O R}\right) * 100,
$$

OR is the odds ratio generated from binary logistic regression analysis and $\mathrm{Pe}$ is the proportion of deaths that have the exposure.

\section{Results}

Table 2 shows birthweight and maternal and sociodemographic characteristics of last-born live births by neonatal survival status in Uganda. Overall, the average proportion of neonatal deaths among LBW babies between 1995 and 2011 was about $3.5 \%$ while the average proportion of neonatal deaths among normal weight babies ( $\geq 2500 \mathrm{~g} \leq 4000 \mathrm{~g})$ during the same period was less than $1 \%$. Cesarean birth was associated with neonatal mortality only in the year 2000-2001 ( $p<0.05)$.

Table 3 shows the distribution of the study variables by birthweight. Statistical significantly higher proportions $(p<0.05)$ of mothers with no formal education had LBW babies in almost all the years except 2011. Similarly, maternal age $<20$ years of age was associated with having higher proportions of LBW babies as shown in the 1995 and 2006 findings $(p<0.01)$.

In all surveys, LBW was significantly associated with neonatal mortality as shown in Table 4 below. The adjusted odds ratio (AOR) for the years in question were as follows: in 1995, 6.2 (95\% CI (2.3 - 17.0), in 2000-2001, 5.3 (95\% CI 1.7 - 16.1), in 2006, 4.3 (1.3 - 14.2), and in 2011, 3.8 (95\% CI 1.3 - 11.2). The 1995 and 2000-2001 data were not adjusted for wealth status due to large amounts of missing data. Birth complications were also not adjusted for in 1995 due to absence of data.

Figure 2 below shows the relationship between birthweight and time-to-death among neonatal mortality cases, combining all the study years. In conjunction with the survival table (not included in the paper), we observed that over $85 \%$ of all neonatal deaths in our study sample occurred in the first week of life. About 95\% of all the LBW $(<2500 \mathrm{~g})$ neonatal deaths occurred within the first week of life. In comparison, about $82 \%$ of deaths among neonates with NBW (2500 g $\leq 4000 \mathrm{~g}$ ) took place within in the first weeks. The rest died later, in the second, third, and fourth weeks. The figure also shows an inverse proportionality relationship between weight and survival. With the exception of an outlier, the neonates with higher birthweights tended to survive longer, i.e. beyond the first week.

The LBW-attributable neonatal mortality in Uganda declined by more than half, from 33.6\% (\%) in 1995 to $15.3 \%$ in 2011 as shown in Table 5 below. Similarly, LBW-attributable neonatal mortality among LBW babies also declined by $10.2 \%$ from $83.9 \%$ to $73.7 \%$ in the same period.

Figure 3 shows a non-uniform but continuous decline of LBW-attributable neonatal mortality in Uganda between 1995 and 2011.

\section{Discussion}

Overall, the odds of neonatal mortality among LBW babies as compared to normal birthweight were reduced by a third, from about 6 times higher in 1995 to 3.8 times higher in 2011. The LBW-attributable neonatal mortality in the population declined by more than half, from $33.6 \%$ in 1995 to $15 \%$ in 2011. This present study is the first of its kind in Uganda and perhaps the whole of east Africa that examines the trends of LBW-attributable mortality over the years. The study reinforces the very few LBW-related studies in Uganda and east Africa by providing new peer-reviewed findings on the contribution of LBW towards neonatal mortality countrywide over a period of over 15 years. The study findings might be useful for auditing the causes of neonatal deaths, and for evaluation, future health planning and policy making aimed at improving neonatal survival. The WHO emphasizes that auditing the causes of neonatal deaths is paramount for effective monitoring and improving mother and child health care [37].

The 3.8 times higher odds of deaths among LBW neonates in 2011 in the present study is consistent with the findings of a related study conducted by Kananura et al. in eastern Uganda in 2012-2013 that indicated a 3.51 mortality odds ratio [36]. Comparable findings were also obtained in a follow-up study in western Uganda, completed in 2006 but analyzed by Marchant et al. in 2012 
Table 2 Distribution of birthweight, maternal and sociodemographic characteristics by neonatal survival status in Uganda, 1995-2011

\begin{tabular}{|c|c|c|c|c|c|c|c|c|c|c|c|c|}
\hline \multirow[t]{3}{*}{ Variables } & \multirow{2}{*}{\multicolumn{3}{|c|}{$\frac{1995}{\text { Survival, } N=1160}$}} & \multirow{2}{*}{\multicolumn{3}{|c|}{$\frac{2000-2001}{\text { Survival, } N=1100}$}} & \multirow{2}{*}{\multicolumn{3}{|c|}{2006}} & \multirow{2}{*}{\multicolumn{3}{|c|}{$\frac{2011}{\text { Survival, } N=(2199)}$}} \\
\hline & & & & & & & & & & & & \\
\hline & $\begin{array}{l}\text { Died } \\
\text { n (\%) }\end{array}$ & $\begin{array}{l}\text { Lived } \\
\text { n (\%) }\end{array}$ & $P$ value & $\begin{array}{l}\text { Died } \\
\text { n (\%) }\end{array}$ & $\begin{array}{l}\text { Lived } \\
\text { n (\%) }\end{array}$ & $P$ value & $\begin{array}{l}\text { Died } \\
\text { n (\%) }\end{array}$ & $\begin{array}{l}\text { Lived } \\
\text { n (\%) }\end{array}$ & $P$ value & $\begin{array}{l}\text { Died } \\
\text { n (\%) }\end{array}$ & $\begin{array}{l}\text { Lived } \\
\mathrm{n}(\%)\end{array}$ & $P$ value \\
\hline \multicolumn{13}{|l|}{ Birthweight } \\
\hline$<2500 \mathrm{~g}$ & $4(3.3)$ & $118(96.7)$ & $<0.01$ & $5(4.6)$ & $104(95.4)$ & $<0.01$ & $5(2.8)$ & $175(97.2)$ & $<0.05$ & $7(2.9)$ & $234(97.1)$ & $<0.05$ \\
\hline$\geq 2500 \mathrm{~g}$ & $6(0.6)$ & $1032(99.4)$ & & $10(1.0)$ & $981(99.0)$ & & $11(0.8)$ & $1323(99.2)$ & & $22(1.1)$ & $1936(98.9)$ & \\
\hline \multicolumn{13}{|l|}{ Maternal age } \\
\hline$<20$ & $1(0.6)$ & $155(99.4)$ & $>0.05$ & $1(0.9)$ & $111(99.1)$ & $>0.05$ & $2(1.4)$ & $138(98.6)$ & $>0.05$ & $2(1.3)$ & $154(98.7)$ & $>0.05$ \\
\hline $20-34$ & $6(0.7)$ & $855(99.3)$ & & $12(1.4)$ & $825(98.6)$ & & $11(1.0)$ & 1105 (99.0) & & $15(1.0)$ & $1496(99.0)$ & \\
\hline $35-49$ & $3(2.1)$ & $140(97.9)$ & & $3(2.0)$ & $148(98.0)$ & & $2(0.8)$ & $254(99.2)$ & & $7(1.6)$ & $427(98.4)$ & \\
\hline Wealth index & $n=392^{b}$ & & & $n=424^{b}$ & & & & & & & & \\
\hline Poor & $1(0.7)$ & $137(99.3)$ & $>0.05$ & $1(0.5)$ & $187(99.5)$ & $>0.05$ & $4(0.9)$ & $442(99.1)$ & $>0.05$ & $7(1.1)$ & $652(98.9)$ & $>0.05$ \\
\hline Middle / Rich & $4(1.6)$ & $250(98.4)$ & & $3(1.3)$ & $233(98.7)$ & & $11(1.0)$ & $1056(99.0)$ & & $17(1.1)$ & $1426(98.9)$ & \\
\hline \multicolumn{13}{|l|}{ Maternal education } \\
\hline No education & $2(1.5)$ & $132(98.5)$ & $>0.05$ & $2(1.6)$ & $124(98.4)$ & $>0.05$ & $3(1.6)$ & $179(98.4)$ & $>0.05$ & $2(1.2)$ & $171(98.8)$ & $>0.05$ \\
\hline Primary & $6(0.9)$ & $653(99.1)$ & & $8(1.6)$ & $605(98.4)$ & & $7(0.8)$ & $857(99.2)$ & & $12(1.0)$ & $1149(99.0)$ & \\
\hline Secondary higher & $2(0.5)$ & $365(99.5)$ & & $5(1.4)$ & $356(98.6)$ & & $5(1.1)$ & $462(98.9)$ & & $11(1.4)$ & 757 (98.6) & \\
\hline \multicolumn{13}{|l|}{ Parity } \\
\hline Primiparous & $3(1.0)$ & $296(99.0)$ & $>0.05$ & $4(1.4)$ & $278(98.6)$ & $>0.05$ & $6(1.7)$ & $356(98.3)$ & $<0.05$ & $3(0.7)$ & $424(99.3)$ & $>0.05$ \\
\hline Para 2-3 & $3(0.6)$ & $532(99.4)$ & & $5(1.0)$ & $483(99.0)$ & & $7(1.1)$ & $622(98.9)$ & & $11(1.2)$ & $945(98.8)$ & \\
\hline Para 4+ & $4(1.2)$ & $322(98.8)$ & & $6(1.8)$ & $323(98.2)$ & & $2(0.4)$ & $520(99.6)$ & & $10(1.4)$ & 709 (98.6) & \\
\hline \multicolumn{13}{|l|}{ Marital status } \\
\hline Single & $1(0.5)$ & $199(99.5)$ & $>0.05$ & $2(1.0)$ & $198(99.0)$ & $>0.05$ & $2(0.7)$ & $277(99.3)$ & $>0.05$ & $3(0.8)$ & $354(99.2)$ & $>0.05$ \\
\hline Married & $9(0.9)$ & $951(99.1)$ & & $14(1.6)$ & $887(98.4)$ & & $13(1.1)$ & $1221(98.9)$ & & $22(1.3)$ & $1722(98.7)$ & \\
\hline \multicolumn{13}{|l|}{ Residence } \\
\hline Rural & $5(1.0)$ & $517(99.0)$ & $>0.05$ & $11(1.5)$ & $737(98.5)$ & $>0.05$ & $10(0.9)$ & $1051(99.1)$ & $>0.05$ & $17(1.1)$ & $1493(98.9)$ & $>0.05$ \\
\hline Urban & $5(0.8)$ & $633(99.2)$ & & $4(1.1)$ & $348(98.9)$ & & $5(1.1)$ & $447(98.9)$ & & $7(1.2)$ & $584(98.8)$ & \\
\hline \multicolumn{13}{|l|}{ Delivery mode } \\
\hline Cesarean & $1(1.4)$ & 71 (98.6) & $>0.05$ & $4(4.4)$ & 87 (95.6) & $<0.05$ & $1(0.8)$ & $122(98.2)$ & $>0.05$ & $5(2.1)$ & $230(97.9)$ & $>0.05$ \\
\hline Normal & $9(0.8)$ & 1079 (99.2) & & $12(1.2)$ & 995 (98.8) & & $14(1.0)$ & $1372(99.0)$ & & $24(1.2)$ & 1940 (98.8) & \\
\hline \multicolumn{13}{|l|}{ Check-up $^{a}$} \\
\hline No & No data & & & $11(1.5)$ & $742(98.5)$ & $>0.05$ & $6(0.7)$ & 866 (99.3) & $>0.05$ & $13(1.5)$ & $843(98.5)$ & $>0.05$ \\
\hline Yes & & & & $4(1.2)$ & $332(98.2)$ & & $9(1.4)$ & 613 (98.6) & & $14(1.1)$ & $1261(98.9)$ & \\
\hline
\end{tabular}

$P$ values were generated from Chi square analysis. Statistical significance $(p<0.05$, two-sided)

${ }^{a}$ complications

${ }^{\mathrm{b}}$ The separate totals(n) for wealth index in 1995 and 2000 shows a deviation from the total (N) due to missing data

[15]. This study estimated the odds of neonatal mortality among LBW newborns relative to NBW newborns at 3.45 [15]. Our findings of $15.3 \%$ LBW-attributable neonatal mortality in 2011 in the population are comparable to the findings of a situation analysis study conducted by the Ministry of Health $(\mathrm{MoH})$ in Uganda in 2008 [38]. The MoH study combined both quantitative and qualitative methods and collected data from 10 districts covering the four conventional regions (Central, Eastern, Western and Northern) in Uganda. In this $\mathrm{MoH}$ study, the health personnel interviewed about perinatal outcomes in the health units indicated that LBW contributed to $16 \%$ of the total newborn deaths [38]. However, the study also acknowledged the underreporting of LBW as a cause of death due to overlaps with infections and breathing difficulties [38].

The results indicated a significantly higher proportion of deaths among LBW babies and this corroborates with findings of other studies [2,3] that show higher mortalities among LBW newborns relative to their NBW counterparts. 
Table 3 Univariate analysis of maternal and sociodemographic characteristics of neonates by birthweight in Uganda, 1995-2011

\begin{tabular}{|c|c|c|c|c|c|c|c|c|c|c|c|c|}
\hline \multirow[t]{2}{*}{ Variables } & \multicolumn{3}{|c|}{$1995, N=1160$} & \multicolumn{3}{|c|}{$2000-2001, N=1100$} & \multicolumn{3}{|c|}{$2006, N=1514$} & \multicolumn{3}{|c|}{$2011, N=2199$} \\
\hline & LBW (\%) & NBW (\%) & $P$ value & LBW & NBW & $P$ value & LBW & NBW & $P$ value & LBW & NBW & $P$ value \\
\hline \multicolumn{13}{|l|}{ Maternal age } \\
\hline$<20$ & $26(16.7)$ & 130(83.3) & $<0.01$ & 15(13.4) & $97(86.6)$ & $>0.05$ & $27(19.1)$ & 114(80.9) & $<0.01$ & $20(12.7)$ & 137(87.3) & $>0.05$ \\
\hline $20-34$ & $81(9.4)$ & $780(90.6)$ & & $77(9.2)$ & $761(90.8)$ & & $112(10.0)$ & 1004(90.0) & & $174(11.5)$ & 1337(88.5) & \\
\hline $35-49$ & $15(10.5)$ & $128(89.5)$ & & $17(11.2)$ & 135(88.8) & & $41(16.0)$ & $216(84.0)$ & & 39(9.0) & $395(91.0)$ & \\
\hline Wealth & $n=392$ & & & $n=424^{\mathrm{a}}$ & & & & & & & & \\
\hline Poor & 15(10.9) & 123(89.1) & $>0.05$ & 19(10.1) & 169(89.9) & $>0.05$ & $61(13.7)$ & $385(86.3)$ & $>0.05$ & 72(10.9) & $587(89.1)$ & $>0.05$ \\
\hline Middle/rich & $26(10.2)$ & 228(89.8) & & $25(10.6)$ & $211(89.4)$ & & $118(11.1)$ & $949(88.9)$ & & 161(11.2) & $1282(88.8)$ & \\
\hline \multicolumn{13}{|l|}{ Education level } \\
\hline No education & $24(17.9)$ & $110(82.1)$ & $<0.01$ & $21(16.7)$ & 105(83.3) & $<0.01$ & $29(15.9)$ & $153(84.1)$ & $<0.05$ & $27(15.6)$ & $146(84.4)$ & $>0.05$ \\
\hline Primary & $67(10.2)$ & $592(89.8)$ & & $60(9.8)$ & $555(90.2)$ & & $101(11.7)$ & $763(88.3)$ & & $121(10.4)$ & 1040(89.6) & \\
\hline Secondary & $31(8.4)$ & 336(91.6) & & $28(7.8)$ & 332(92.2) & & $49(10.5)$ & 418(89.5) & & $85(11.1)$ & 684(88.9) & \\
\hline \multicolumn{13}{|l|}{ Parity } \\
\hline Primiparous & $45(15.1)$ & 254(84.9) & $<0.01$ & $27(9.6)$ & 255(90.4) & $>0.05$ & $50(13.8)$ & $312(86.2)$ & $>0.05$ & $58(13.6)$ & $368(86.4)$ & $>0.05$ \\
\hline Para 2-3 & $48(9.0)$ & 487(91.0) & & $51(10.5)$ & 437(89.5) & & $69(11.0)$ & $560(89.0)$ & & $98(10.3)$ & $858(89.7)$ & \\
\hline Para 4+ & $29(8.9)$ & 297(91.1) & & $31(9.4)$ & $300(90.6)$ & & $60(11.5)$ & $462(88.5)$ & & 77(10.7) & 643(89.3) & \\
\hline \multicolumn{13}{|l|}{ Place of residence } \\
\hline Rural & $67(12.8)$ & $455(87.2)$ & $<0.05$ & $76(10.1)$ & 674(89.9) & $>0.05$ & 134(12.6) & $928(87.4)$ & $>0.05$ & $167(11.1)$ & 1343(88.9) & $>0.05$ \\
\hline Urban & $55(8.6)$ & $583(91.4)$ & & $33(9.4)$ & 319(90.6) & & $46(10.2)$ & 406(89.8) & & $66(11.1)$ & $526(88.9)$ & \\
\hline \multicolumn{13}{|l|}{ Marital status } \\
\hline Single & $25(12.5)$ & $175(87.5)$ & $>0.05$ & $29(14.5)$ & $171(85.5)$ & $<0.05$ & $39(13.9)$ & $241(86.1)$ & $>0.05$ & $36(10.1)$ & $321(89.9)$ & $>0.05$ \\
\hline Married & $97(10.1)$ & $863(89.9)$ & & $80(8.9)$ & $821(91.1)$ & & $141(11.4)$ & 1093(88.6) & & 197(11.3) & 1547(88.7) & \\
\hline \multicolumn{13}{|l|}{ Cesarean } \\
\hline Yes & $4(5.6)$ & $68(94.4)$ & $>0.05$ & 11(11.8) & $82(88.2)$ & $>0.05$ & $24(19.7)$ & $98(80.3)$ & $<0.01$ & $29(12.3)$ & 206(87.7) & $>0.05$ \\
\hline No & 118(10.8) & $970(89.2)$ & & $99(9.8)$ & $909(9.2)$ & & 154(11.1) & 1232(88.9) & & 212(10.8) & 1752(89.2) & \\
\hline \multicolumn{13}{|l|}{ Check-up } \\
\hline No & No data & & & $72(9.5)$ & $683(90.5)$ & $>0.05$ & $105(12.0)$ & 767(88.0) & $>0.05$ & $87(10.2)$ & 769(89.8) & $>0.05$ \\
\hline Yes & & & & $34(10.1)$ & $302(89.9)$ & & 73(11.8) & 1315(88.1) & & $143(11.2)$ & 1132(88.8) & \\
\hline
\end{tabular}

LBW refers to low birthweight $(<2500 \mathrm{~g})$, NBW refers to normal birthweight $(\geq 2500 \mathrm{~g}-4000 \mathrm{~g})$. $P$ values were obtained from chi square test

${ }^{a}$ The separate totals $(\mathrm{n})$ for wealth index in 1995 and 2000 shows a deviation from the total (N) due to missing data

Although cesarean births have been associated with mortality as also shown by the findings $(p<0.05)$ for the year 2000-2001 in Table 2, in 2006 and 2011 however, the findings $(p>0.05)$ indicated improvements in obstetric services that has enabled the survival of many cesarean birth babies.
Figure 2 showed that about $85 \%$ of neonatal deaths occurred in the first week after birth. This is close to the estimate of a recent $\mathrm{MoH}$ report on maternal, perinatal and child death review that indicated about $75 \%$ neonatal deaths in the first week [39]. The inverse proportional

Table 4 Logistic regression analysis showing association between low birthweight and neonatal mortality in Uganda, 1995 - 2011

\begin{tabular}{|c|c|c|c|c|}
\hline \multirow{3}{*}{ Variable } & \multicolumn{4}{|c|}{ Adjusted odds ratios (95\% confidence interval) } \\
\hline & 1995 & $2000-2001$ & 2006 & 2011 \\
\hline & $N=1160$ & $N=1100$ & $N=1519$ & $N=2223$ \\
\hline \multicolumn{5}{|l|}{ Birthweight } \\
\hline Low birthweight & $6.2(2.3-17.0)^{b}$ & $5.3(1.7-16.1)^{b}$ & $4.3(1.3-14.2)^{a}$ & $3.8(1.3-11.2)^{a}$ \\
\hline Normal birthweight & 1.0 & 1.0 & 1.0 & 1.0 \\
\hline
\end{tabular}




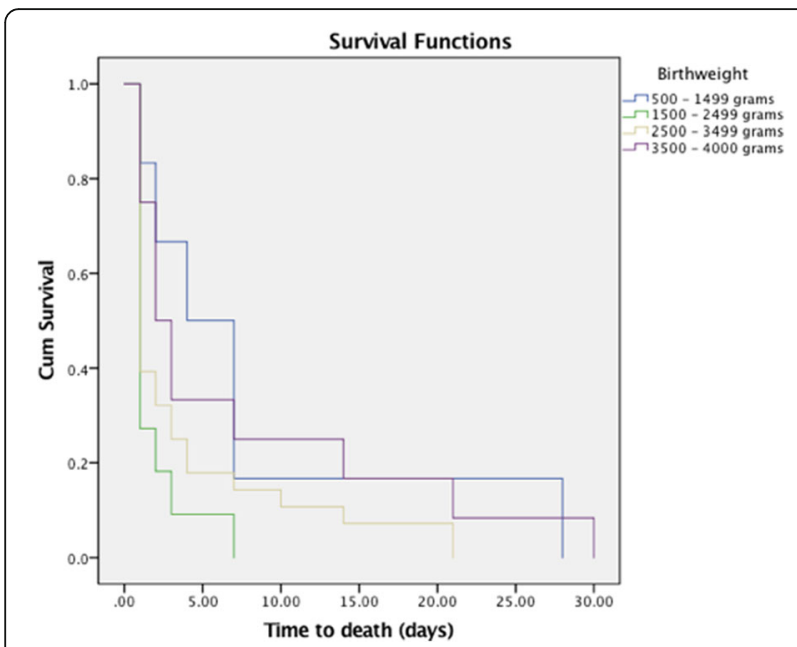

Fig. 2 Kaplan-Meier survival curves by birthweight for neonates in Uganda between 1995 and 2011. Cum - cumulative

relationship indicated by the trends of birthweight versus time-to-death among neonatal deaths in Fig. 2 concurs with findings from a hospital-based study in Dhaka, Bangladesh [40]. The findings in Fig. 2 also implied that the risk of neonatal death is inversely proportional to birthweight and are in agreement with several other studies [40-43]. However, our data on age at death (days) appeared to have been aggregated in terms of 7 days (weekly) and not the actual mortality days. This slightly compromised the accuracy of the Kaplan Meier's survival curve in our study in terms of days of survival.

According to a facility-based study by Hedstrom et al. in central Uganda that admitted neonates born between December 2005 and September 2008, 89\% of neonatal deaths among LBW neonates weighing under $1000 \mathrm{~g}$ could be attributable to LBW [43]. Another study by Marchant et al. [15] that utilized data collected in 2006 in western Uganda also estimated a $71 \%$ LBW-attributable neonatal mortality among LBW neonates. Both of these

Table 5 Low birthweight-attributable neonatal mortality risk proportions in Uganda between 1995 and 2011

\begin{tabular}{lll}
\hline & Year of survey & $\begin{array}{l}\text { Attributable risk } \\
\text { fraction (\%) }\end{array}$ \\
\hline Among LBW neonates (AF) & 1995 & 83.9 \\
& $2000-2001$ & 81.1 \\
& 2006 & 76.7 \\
In the entire population (PAF) & 2011 & 73.7 \\
& 1995 & 33.6 \\
& $2000-2001$ & 27.0 \\
& 2006 & 24.0 \\
& 2011 & 15.3 \\
\hline
\end{tabular}

LBW low birthweight, AF Attributable Fraction, PAF Population Attributable Fraction

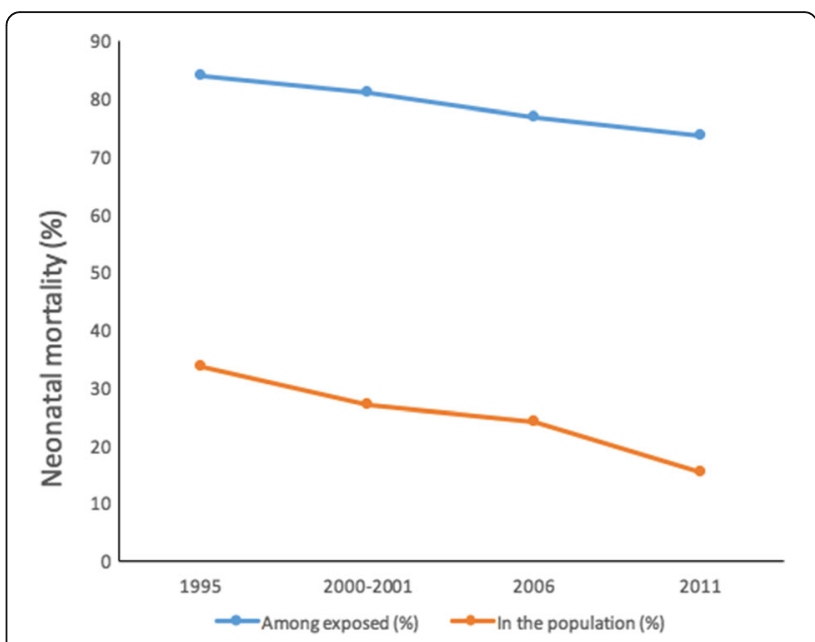

Fig. 3 Graphical representation of low birthweight-attributable neonatal mortality trends in Uganda between 1995 and 2011

findings are comparable with the LBW-attributable mortality estimates among LBW babies in the whole country in this present study.

Neonatal mortality accounts for about $40 \%$ of global under-five mortality [44]. In Uganda, in recent years, it was estimated that about 45,000 neonates die every year [20]. By extension of our findings, this corresponds to approximately 7000 (15.3\%) neonatal deaths attributable to LBW in 2011. Although our findings could be a slight underestimation given the many unrecorded births (about $45 \%$ in 2011) [43] and unregistered neonatal deaths, they provide comparable national estimates that can be used for advocacy and countrywide public health planning to reduce LBW-attributable neonatal deaths. For instance, the successful Kangaroo Mother Care project for premature and LBW newborns initiated by Uganda Newborn Study project (UNEST) in 2007-2011 in Iganga and Mayuge district [45] could be implemented countrywide.

The greatest national decline of LBW-attributable mortality estimated in 2011 in our study is a notable finding that could be attributed to the efforts of the inter-agency national Newborn Steering Committee (NSC) [46]. The NSC, which was initiated in 2006, ensured rapid policy adaptation and implementations both at the health facility and community levels in the few years to 2011 [46]. It was mandated by the $\mathrm{MoH}$ to spearhead comprehensive service delivery and community-and health facility-based training [46, 47]. Our findings thus reveal that the policy changes and its implementation may have had a profound positive impact on the survival of LBW newborns during this period. The findings indicate that it is possible to eliminate unnecessary neonatal deaths due to LBW and make significant contributions towards achieving the SDG 3.2 target that aims to lower neonatal death rate to 12 per 1000 live births by 2030 [23]. Further, both the present 
study findings and the NSC initiative could be of keen interest to similar countries (with high neonatal mortalities) for policy making and study replications with the aim of improving LBW neonatal survival, for instance, in the Philippines, where the decline of neonatal deaths has stagnated [48].

Also, the Uganda Newborn Study (UNEST) Project partly contributed to the decline in mortality of LBW and preterm newborns in parts of eastern Uganda and consequently contributed to the overall national decline during this period [45].

The survival analysis indicated that the rate of decline in LBW-attributable mortality in the 5 -year periods increased from 6.6\% between 1995 and 2000-2001 to 8.7\% between 2006 and 2011 in the population (Table 5). However, between the two periods, there was a significant deceleration in the decline to $3.0 \%$ between 2000 and 2001 and 2006 (Fig. 3 and Table 5). This could potentially be due to the $20 \%$ decline in the use of family planning methods among $<20$ years old sexually active girls during this period as noted by the analytical overview of the Ugandan child report [49]. This could have led to increased teenage pregnancies. LBW are common among teenage mothers $(<20$ years $)$ [7] and the mortality among babies born to younger mothers in Uganda was also notably high between 1995 and 2005 [22]. Nevertheless, our findings in Table 2 did not show any significant higher mortality numbers among the $<20$ years old mothers, perhaps because of the few number of births in this age-group in our sample selection. However, statistically reasonable numbers in 2006 showed a significant association between primipara mothers (most of whom were younger mothers (Table 3)) and neonatal mortality. A study conducted by Andualem et al. in western Uganda between 2005 and 2008 revealed that over $82 \%$ of female students had unmet sexual/reproductive health counseling needs [50]. Lack of knowledge about the signs of pregnancy complications has been linked to birth unpreparedness in Uganda [51], a consequent risk factor for neonatal deaths, including LBW deaths. A comparative development study by Kevin Croke [52] also highlighted the decline in the health system gains in Uganda between 2001 and 2006 due to political shocks related to removal of presidential term limits. Financing of the health care system was negatively affected. This could partly account for the rise in LBW-neonatal deaths during this period. The specialized care of LBW babies requires extra financing compared to NBW. The direct impact of the decline in health system gains on survival of LBW detected by the present study is consistent with WHO/UNICEF observations that survival of LBW neonates, a high-risk infant group, is among the most sensitive indicators to assess the progress of maternal and child health status in a country [2].
There was no statistically significant association between place of residence, maternal education, marital status, wealth status, maternal age, and neonatal mortality, $(P>0.05)$ (Table 2). Although studies vary in their findings concerning the association between these socio-demographic and maternal factors (including parity) and neonatal mortality [53], many study findings have indicated an association between single motherhood [54], teenage maternal age [55-57], lack of education [56], rural residence [57] and neonatal mortality. A systematic review of 17 studies up to the year 2013 in SSA [55] indicated that socio-demographic and maternal risk factors are much more prevalent among teenage mothers as compared to adult mothers [55]. With the decentralized system in Uganda, further analytical research at the districts or regional levels on the effect of socio-demographic factors on birthweight and neonatal deaths would provide more robust findings for monitoring, policy making and interventions. However, at the national level, comprehensive measurement and recording of birthweight need to be made possible, irrespective of whether a child is born at home or at the hospital. As a national policy driven initiative, the provision of weighing scales to health volunteers and midwives at the community level, even on a shared basis based on proximity and locality, is feasible and could be very effective for monitoring neonatal health countrywide. Apart from improving accuracy on birthweight data collection, the availability of weighing scales could also be a profound campaign tool for lowering LBW incidences by highlighting preventive measures. Affordable and easy to maintain mechanical weighing scales have previously been used at the community level in over 400 villages in western Kenya [58]. Although it was on a small scale, the initiative was profoundly successful, as shown by an increase in the birthweight measurements of newborns of about $54 \%$, from $43 \%$ to $97 \%$ [58]. The current study could thus give the impetus to communities and local organizations to take initiatives and improve the survival of LBW neonates. Further, as LBW is an underlying cause of $60-80 \%$ of all neonatal deaths globally $(2,3)$ and about $15 \%$ of neonatal deaths in Uganda (present study 2011 findings), continuous data collection on birthweights that supports research, monitoring, and strategic preventive interventions could be a formidable approach to curbing neonatal deaths and overall health systems strengthening both globally and in Uganda.

Although our study largely indicated no significant associations between cesarean birth, pregnancy complications and neonatal mortality for most of the years, a number of studies have found associations between cesarean births [57, 59], pregnancy complications [59] and neonatal deaths. There were inconsistencies in our findings with regard to the significant associations between socio-demographic factors and LBW across all the 
study years $(p<$ or $>0.05)$ (Table 3$)$. However, there were higher proportions of LBW babies among teenage and uneducated mothers in all the survey years. Teenage pregnancy was associated with LBW only in 1995 and 2006. These findings corroborate study findings elsewhere in rural India [60] and in several SSA countries $[7,61]$ that strongly indicate that young maternal age is associated with LBW. A study in Brazil, however, found an association between teenage pregnancy and LBW only when marital partners (an economic factor) were lacking [62].

\section{Methodological considerations}

The random sampling of data across the entire country and the standardized nature of data collection method of the DHS strengthen the external validity of our study and enable global comparability among countries. Weighting the data for the years 2000, 2006 and 2011enabled us to adjust for disproportionate sampling and non-response. This improved the national representativeness and validity of the study estimates. The 1995 dataset was not weighted and the results for that year are slightly less representative. However, the results are still valid, due to the fact that there was only a small difference when weighted and unweighted results of all the other years were compared. The national representativeness of the 1995 data was only dependent on the random sampling across the entire country and the standardized nature of DHS data collection for its reliability.

The repeated findings of significant associations between LBW and neonatal mortality across all surveys confirm the existing evidence of association and the internal validity of this present study. Nonetheless, our study could not confirm the causal association because the exact causes of newborn deaths were not ascertained medically. The in-depth use of the nationally representative DHS datasets in this study has revealed the need to improve data collection techniques and to include other similarly important variables such as diagnostic causes of death among individual children, for example, birth asphyxia.

Another limitation of our study was that although hospital births recorded and/or communicated birthweights, over $65 \%$ were from mothers ' recall and the rest from the health card, and we cannot therefore completely dismiss the possibility of recall bias. This also applies to the 1995 data that included both hospital and home births. Nevertheless, child birth is a significant event in a mother's life and with our study selection of the most recent birth experience, there is a very high possibility that the mothers recalled correct birthweights. Moreover, for the years 2000 to 2011, birthweight data concerned solely information regarding hospital born babies because these were measured birthweights and not estimated weights as in-home births, where birthweights are mainly estimated based on the physical size of the body parts such as foot length, chest or head [63]. A study in Uganda compared the accuracy of a proxy measure of LBW by midwives in a hospital-based setting showed an accuracy of over $80 \%$. However, the study also noted the limitation that the findings may not reflect the actual situation in the communities where less skilled community volunteers assist in most births, and their estimates of cut-offs are prone to bias [63]. Elimination of macrosomic newborns improved the validity of our findings.

Although the 1995 data included both home and hospital births, which undermined the consistency of the study methodology across years, preliminary analysis indicated that among the selected sample of newborns with birthweight measures in 1995 , only $3.5 \%$ of the births were home births (or perhaps on the way to the hospital). The 1995 data thus has a reasonable degree of consistency with other survey years. However, the selection of only hospital births in other survey years improved the quality and validity of the findings for those years.

The recording of neonatal survival data from day 0 to 30 by the DHS allowed us to clearly categorize our outcome variable and investigate risk factors across all the survey years with consistency. Given the large number of home births (about 50\%) in all the surveys, both the LBW and neonatal deaths were likely underreported.

The birthweight data are prone to rounding-off or aggregation into $500 \mathrm{~g}$-weight intervals which could have slightly compromised the accuracy of Kaplan-Meier's survival analysis in this study. This aggregation of data was observed in a study by Channon et al. [64]. However, the fact that over $90 \%$ of LBW neonatal deaths in our study occurred in the first week is quite consistent with global WHO findings that $75 \%$ of neonatal deaths occur in the first week [65], given the high-risk group of LBW in a low-income country.

\section{Conclusion}

Low birthweight is associated with neonatal mortality and contributes to a substantial proportion of neonatal deaths in Uganda. Although significant progress has been made to reduce newborn deaths attributed to LBW, by 2011 , about $74 \%$ of all LBW neonates died in the neonatal period. This implies that the health system in place has been inadequate to meet the challenge of ensuring LBW survival. There is also profound need to strengthen both birth and neonatal death registration irrespective of whether the infants are born at home or at the health centers. The decentralized health system in Uganda can enable community health workers (CHW) and the village health teams (VHT) in liaison with the sub-counties and the districts to close the existing gaps concerning neonatal birth and death audits. This will 
enable robust and continuous research and monitoring of the progress of LBW neonatal survival. Our study presents national estimates of risks and mortality trends that provide national basis for continual evaluation and policy recommendations to prevent LBW and minimize risks of neonatal deaths. A holistic approach to reduce the incidence of preventable LBW babies could be fostered to reduce these mortality rates. Viable fronts that could be strengthened include sexual education in schools to prevent teenage pregnancies, complementing nutritional diet of pregnant mothers, HIV testing, ensuring that all pregnant mothers use mosquito nets, training of health workers, and promoting antenatal care visits and hospital births. Enhancing the quality of postnatal care could also reduce mortality incidence of LBW newborns.

\section{Abbreviations}

AF: Attributable fraction; AOR: Adjusted odds ratio; CHW: Community health workers; DHS: Demographic and health survey; EA: East Africa; LBW: Low birthweight; MDG: Millennium development goals; $\mathrm{MoH}$ : Ministry of Health; NBW: Normal birthweight; NSC: Newborn Steering Committee; PAF: Population attributable fraction; SDG: Sustainable development goal: SGA: Small for gestational age; SSA: Sub-Saharan Africa; UNAP: Uganda nutrition action plan; UNEST: Uganda newborn study; VHT: Village health teams

\section{Acknowledgements}

Special gratitude to the Demographic and Health Survey program for making the datasets available for this study.

\section{Availability of data and materials}

Authorization to use the secondary, unrestricted Uganda DHS data was obtained from MEASURE DHS after a requisition was made through their webpage by registration, selection of country and submission of a brief description of the study. The DHS program is authorized by the country, Uganda to distribute data for research aimed at improving public health. Procedures and questions for standard DHS surveys have been approved by both ICF Institutional Review board and the review board in the host country Uganda. Both of which ensure that DHS complies with the protection of the dignity and rights of human participants and the norms of the country.

\section{Authors' contributions}

MOA Conceptualized the research study, developed the study design, acquired data, analyzed and drafted the manuscript. AA Contributed to the interpretation of data and to the writing of the manuscript. BOA Involved in developing the study design, interpretation and contributed to the writing of the manuscript. MOA, AA, BOA Read and approved the final draft of the manuscript.

\section{Ethics approval and consent to participate}

Approval for utilization of Uganda DHS data for this study was obtained from ICF Macro Int. Data was accessible from: https://dhsprogram.com/Data/. Uganda National guidelines for secondary (third party) research that use unrestricted, publicly available and unlinked data that does not identify individuals or communities are exempted from ethical approval requirement During data collection process by the primary data collector, ICF Macro Int, a written informed consent was sought for each willing participant by MEASURE DHS before data collection commenced. The statement of consent emphasize to the participant that they are at liberty to terminate or decline to respond at any stage of the interview process. Those unwilling were excluded from the study. The participants remained anonymous and the DHS approved procedures ensure that future identification of any individual participant or community is practically impossible. These measures are thus in adherence with both the international guidelines for epidemiological studies of the Council of International Organizations of Medical Sciences (CIOMS) and the Uganda National guidelines for research involving human subjects. Further, the measures abide by the United States
Department of Health and Human Services regulations for the protection of human subjects.

\section{Competing interests}

The authors declare that they have no competing interests.

\section{Publisher's Note}

Springer Nature remains neutral with regard to jurisdictional claims in published maps and institutional affiliations.

Received: 26 April 2017 Accepted: 15 May 2018

Published online: 30 May 2018

References

1. United Nations Children's Fund and World Health Organization. Low birthweight: country, regional and global estimates. New York: UNICEF; 2004

2. World Health Organization. Care of the preterm and/or low-birth-weight newborn. [Updated 2017]. Available from: http://www.who.int/maternal_ child_adolescent/newborns/prematurity/en/. Accessed July 2017.

3. Lawn J, Blencowe H, Oza S, You D, Lee A, Waiswa P, et al. Every newborn: progress, priorities, and potential beyond survival. Lancet. 2014;384(9938):189-205.

4. Ministry of Health and Family Welfare (India). India Newborn Action Plan: Government of India. New Delhi: 2014.

5. Office of the Registrar General and Census Commissioner (India). Causes of death in India 2010-2013 [data table online]. c2010-2013. Available from: http://www.censusindia.gov.in/2011-common/Sample_Registration_System. html. Accessed 11 Nov 2016.

6. Official Statistics of Sweden. Statistics - Health and Medical Care (Sweden), 2015. Pregnancies, Deliveries and Newborn Infants. The Swedish Medical Birth Register 1973-2014 Assisted Reproduction, treatment 1991-2013.

7. Chibwesha C, Zanolini A, Smid M, Vwalika B, Phiri Kasaro M, Mwanahamuntu $M$, et al. Predictors and outcomes of low birth weight in Lusaka, Zambia. Int J Gynecol Obstet. 2016;134(3):309-14.

8. Nkyekyer K. Twin and singleton births in Ghana - a case-control study. Twin Res. 2002;5(04):265-9.

9. Kayode G, Amoakoh-Coleman M, Agyepong I, Ansah E, Grobbee D, Klipstein-Grobusch K. Contextual risk factors for low birth weight: a multilevel analysis. PLoS One. 2014;9(10):e109333.

10. Juárez S, Merlo J. Revisiting the effect of maternal smoking during pregnancy on offspring birthweight: a quasi-experimental sibling analysis in Sweden. PLoS One. 2013;8(4):e61734.

11. Xiao $P$, Zhou $Y$, Chen $Y$, Yang $M$, Song $X$, Shi $Y$, et al. Association between maternal HIV infection and low birth weight and prematurity: a metaanalysis of cohort studies. BMC Pregnancy Childbirth. 2016;16:243. https:// doi.org/10.1186/s12884-016-1044-3.

12. Guyatt $H$, Snow R. Impact of malaria during pregnancy on low birth weight in sub-Saharan Africa. Clin Microbiol Rev. 2004;17(4):760-9.

13. Registrar General of India and the Centre for Global Health Research. Causes of Death Statistics 2010-2013. [Updated 2015]. Available from: http://www. cghr.org/2015/12/causes-of-death-in-india-2010-2013/.

14. Lawn JE, Cousens SN, Wilczynska K. Estimating the causes of four million neonatal deaths in the year 2000: statistical annex-the world health report 2005. Geneva: World Health Organization; 2005.

15. Marchant T, Willey B, Katz J, Clarke S, Kariuki S, Ft K, et al. Neonatal mortality risk associated with preterm birth in East Africa, adjusted by weight for gestational age: individual participant level meta-analysis. PLoS Med. 2012; 9(8):e1001292

16. Welaga P, Moyer C, Aborigo R, Adongo P, Williams J, Hodgson A, et al. Why are babies dying in the first month after birth? A 7-year study of neonatal mortality in northern Ghana. PLoS One. 2013;8(3):e58924.

17. Aslam H, Saleem S, Afzal R, lqbal U, Saleem S, Shaikh M, et al. Risk factors of birth asphyxia. Ital J Pediatr. 2014;40:94. https://doi.org/10.1186/s13052-0140094-2.

18. Shah G, Budhathoki S, Das B, Mandal R. Risk factors in early neonatal sepsis. Kathmandu Univ Med J (KUMJ). 2006;4(2):187-91.

19. Siakwa M, Kpikpitse D, Laryea T, Ankobil A, Dare S, Ebu N. A Five-year neonatal mortality trend in a Ghanaian teaching hospital after the implementation of strategies to achieve the millennium development goal. Int J Pediatrics Child Health. 2014;2(1):043-9. 
20. Ministry of Health. Situation analysis of newborn health in Uganda: current status and opportunities to improve care and survival. Kampala: government of Uganda. Save the children, UNICEF, WHO; 2008.

21. The Republic of Uganda: Roadmap for Accelerating the Reduction of Maternal and Neonatal Mortality and Morbidity in Uganda: Government of Uganda; 2007-2015.

22. Uganda Bureau of Statistics (UBOS) and Macro International Inc. Uganda Demographic and Health Survey 2006. Calverton: UBOS and Macro International Inc.; 2007.

23. Sustainable development goals - United Nations. United Nations Sustainable Development. 2016. Available from: http://www.un.org/sustainabledevelopment/ sustainable-development-goals/. Accessed 01 Dec 2016.

24. World Population Review. Uganda Population 2016. [Updated 2016]. Available from: http://worldpopulationreview.com. Accessed 20 Nov 2016.

25. The World Bank. World Development Indicators (WDI). [Updated 2016]. Available from: http://databank.worldbank.org/data/reports.aspx?source= world-development-indicators. Accessed 21 Nov 2016.

26. Uganda Bureau of Statistics (UBOS) (Uganda), Republic of Uganda; 2014 Statistical Abstract.

27. Xu K, Evans DB, Kadama P, Nabyonga J, Ogwal PO, Nabukhonzo P, et al. Understanding the impact of eliminating user fees: utilization and catastrophic health expenditures in Uganda. Soc Sci Med. 2006;62(4):866-76.

28. Uganda Bureau of Statistics (UBOS) and ICF International Inc. 2012. Uganda Demographic and Health Survey 2011. Kampala: UBOS and Calverton: ICF International Inc

29. Statistics Department/Uganda and Macro International. Uganda Demographic and Health Survey, 1995. Calverton: Statistics Department/ Uganda and Macro International; 1996.

30. Measure DHS. Guide to demographic and health survey statistics: methodology for the measure DHS phase III project, implemented from 2008-2013. 2006.

31. ICF International. MEASURE DHS Biomarker Field Manual. Calverton: ICF International; 2012

32. Macro international Inc. Sampling manual. DHS-III basic documentation no. 6. Calverton: Macro international Inc; 1996

33. Ota E, Haruna M, Suzuki M, Anh D, Tho L, Tam N, et al. Maternal body mass index and gestational weight gain and their association with perinatal outcomes in Viet Nam. Bull World Health Organ. 2011;89(2):127-36.

34. Said A, Manji K. Risk factors and outcomes of fetal macrosomia in a tertiary Centre in Tanzania: a case-control study. BMC Pregnancy Childbirth. 2016;16:243. https://doi.org/10.1186/s12884-016-1044-3.

35. Blanc AK, Wardlaw T. Monitoring low birth weight: an evaluation of international estimates and an updated estimation procedure. Bull World Health Organ. 2005;83(3):178-85.

36. Kananura R, Tetui M, Mutebi A, Bua J, Waiswa P, Kiwanuka S, et al. The neonatal mortality and its determinants in rural communities of eastern Uganda. Reprod Health. 2016;13:13. https://doi.org/10.1186/s12978-016-0119-y.

37. World Health Organization. Making every baby count: audit and review of stillbirths and neonatal deaths, 2016. Geneva: World Health Organization; 2016.

38. Ministry of Health. Situation analysis of newborn health in Uganda. Kampala: Government of Uganda; 2008.

39. Ministry of Health. Situation analysis of newborn health in Uganda: current status and opportunities to improve care and survival. Kampala: Government of Uganda. Save the Children, UNICEF, WHO; 2008

40. Yasmin S, Osrin D, Paul E, Costello A. Neonatal mortality of low-birth-weight infants in Bangladesh. Bull World Health Organ. 2001;79(7):608-14.

41. Golestan M, Fallah R, Akhavan Karbasi S. Neonatal mortality of low birth weight infants in Yazd — Iran. Early Hum Dev. 2008;84:S26.

42. Gaiva M, Fujimori E, Sato A. Neonatal mortality in infants with low birthweight. Revista da Escola de Enfermagem da USP. 2014;48(5):778-86.

43. Hedstrom A, Ryman T, Otai C, Nyonyintono J, McAdams R, Lester D, et al. Demographics, clinical characteristics and neonatal outcomes in a rural Ugandan NICU. BMC Pregnancy Childbirth. 2014;14:327. https://doi.org/10. 1186/1471-2393-14-327.

44. Wang $H$, Liddell CA, Coates MM, Mooney MD, Levitz CE, Schumacher $A E$, et al. Global, regional, and national levels of neonatal, infant, and under-5 mortalities during 1990-2013: a systematic analysis for the global burden of disease study 2013. The Lancet (London, England). 2014;384(9947):957-79.
45. Waiswa P, Peterson S, Namazzi G, Ekirapa E, Naikoba S, Byaruhanga R, et al. The Uganda newborn study (UNEST): an effectiveness study on improving newborn health and survival in rural Uganda through a community-based intervention linked to health facilities - study protocol for a cluster randomized controlled trial. Trials. 2012;13:213. https://doi.org/10.1186/17456215-13-213.

46. Newborn Steering Committee. Kampala. Uganda: Save the Children, Healthy Child Uganda, UNICEF, on behalf of the national Newborn Steering Committee: 2011. Newborn Health Implementation Framework Standards for Newborn Health Services: Health Facility Assessments.

47. Mbonye A, Sentongo M, Mukasa G, Byaruhanga R, Sentumbwe-Mugisa O, Waiswa $P$, et al. Newborn survival in Uganda: a decade of change and future implications. Health Policy Plan. 2012;27(suppl 3):iii104-17.

48. Kraft A, Nguyen K, Jimenez-Soto E, Hodge A. Stagnant neonatal mortality and persistent health inequality in middle-income countries: a case study of the Philippines. PLoS One. 2013;8(1):e53696.

49. Walakira E.J.D., Muhangi S.. Munyuwiny F,. Matovu E,. Awich I., Ddumba Nyanzi J. et al. (2016). The state of the Ugandan child - an analytical overview. Kampala/Washington DC: USAID/QED.

50. Boltena A, Khan F, Asamoah B, Agardh A. Barriers faced by Ugandan university students in seeking medical care and sexual health counselling: a cross-sectional study. BMC Public Health. 2012;12:986. https://doi.org/10. 1186/1471-2458-12-986.

51. Sandberg J, Odberg Pettersson K, Asp G, Kabakyenga J, Agardh A Inadequate knowledge of neonatal danger signs among recently delivered women in southwestern rural Uganda: a community survey. PLoS One. 2014;9(5):e97253.

52. Croke K. The political economy of child mortality decline in Tanzania and Uganda, 1995-2007. Stud Comp Int Dev. 2012:47(4):441-63.

53. Berhan $Y$, Berhan A. A meta-analysis of socio-demographic factors for perinatal mortality in developing countries: a subgroup analysis of the National Surveys and small-scale studies. Ethiop J Health Sci. 2014;24(0):41.

54. Izugbara C. Single motherhood and neonatal and infant mortality in Sierra Leone, Burkina Faso and Burundi. Public Health. 2016;135:122-30.

55. Ramaiya A, Kiss L, Baraitser P, Mbaruku G, Hildon Z. A systematic review of risk factors for neonatal mortality in adolescent Mother's in sub Saharan Africa. BMC Res Notes. 2014;7(1):750.

56. Mekonnen Y, Tensou B, Telake D, Degefie T, Bekele A. Neonatal mortality in Ethiopia: trends and determinants. BMC Public Health. 2013;13:483. https:// doi.org/10.1186/1471-2458-13-483.

57. Ezeh O, Agho K, Dibley M, Hall J, Page A. Determinants of neonatal mortality in Nigeria: evidence from the 2008 demographic and health survey. BMC Public Health. 2014;14:521. https://doi.org/10.1186/1471-2458-14-521.

58. Gisore P, Shipala E, Otieno K, Rono B, Marete I, Tenge C, et al. Community based weighing of newborns and use of mobile phones by village elders in rural settings in Kenya: a decentralised approach to health care provision. BMC Pregnancy Childbirth. 2012;12:15. https://doi.org/10.1186/1471-2393-12-15.

59. Arunda M, Emmelin A, Asamoah B. Effectiveness of antenatal care services in reducing neonatal mortality in Kenya: analysis of national survey data. Glob Health Action. 2017;10(1):1328796.

60. Borah M, Agarwalla R. Maternal and socio-demographic determinants of low birth weight (LBW): a community-based study in a rural block of Assam. J Postgrad Med. 2016;62(3):178.

61. Mombo-Ngoma G, Mackanga J, González R, Ouedraogo S, Kakolwa M, Manego R, et al. Young adolescent girls are at high risk for adverse pregnancy outcomes in sub-Saharan Africa: an observational multicountry study. BMJ Open. 2016;6(6):e011783.

62. Guimarães A, Bettiol H, Souza L, Gurgel R, Almeida M, Ribeiro E, et al. Is adolescent pregnancy a risk factor for low birth weight? Rev Saude Publica. 2013;47(1):11-9.

63. Elizabeth N, Christopher O, Patrick K. Determining an anthropometric surrogate measure for identifying low birth weight babies in Uganda: a hospital-based cross-sectional study. BMC Pediatr. 2013;13:54. https://doi. org/10.1186/1471-2431-13-54.

64. Channon A, Padmadas S, McDonald J. Measuring birth weight in developing countries: does the method of reporting in retrospective surveys matter? Matern Child Health J. 2010;15(1):12-8.

65. Lawn JE, Cousens S, Zupan J. 4 million neonatal deaths: when? Where? Why? Lancet. 2005:365:891-900. https://doi.org/10.1016/S01406736(05)71048-5. 